\title{
PARÂMETROS SOLO-MÁQUINA EM FUNÇÃO DE DOSES DE RESÍDUOS VEGETAIS E PROFUNDIDADES DE DEPOSIÇÃO DE ADUBO EM SEMEADURA DIRETA ${ }^{1}$
}

\author{
KARINA M. KAMIMURA ${ }^{2}$, RENATO LEVIEN ${ }^{3}$, CARLOS R. TREIN ${ }^{4}$, \\ HENRIQUE DEBIASI ${ }^{5}$, OSMAR CONTE ${ }^{6}$
}

\begin{abstract}
RESUMO: O tráfego contínuo e inadequado de máquinas em solos sob semeadura direta tem provocado alterações dos atributos físicos e mecânicos dos solos, influenciando, dessa forma, na produtividade das culturas. O experimento foi conduzido na Estação Experimental Agronômica da Universidade Federal do Rio Grande do Sul, no município de Eldorado do Sul - RS, num Argissolo Vermelho distrófico típico, com o objetivo de quantificar a força de tração e obter informações sobre os atributos físicos do solo, em semeadura direta sobre resíduos de aveia-preta e ervilhaca parcialmente decomposta. O delineamento experimental utilizado foi em blocos casualizados, com parcelas subsubdivididas, sendo, nas parcelas principais, doses de resíduos da cultura de inverno ( 0 ; 1,$3 ; 2,6 ; 3,2 ; 3,8$ e $5,1 \mathrm{Mg} \mathrm{ha}^{-1}$ ) de palha de aveia-preta consorciada com ervilhaca, nas subparcelas profundidades de atuação da haste sulcadora de adubo $(0,06$ e $0,12 \mathrm{~m})$ e nas subsubparcelas tráfegos dos rodados do trator e colhedora. Os atributos físicos do solo foram afetados pelo tráfego dos rodados da máquina. A força de tração foi influenciada pela profundidade de atuação das hastes sulcadoras e o tráfego dos rodados.
\end{abstract}

PALAVRAS-CHAVE: atributos físicos do solo, força de tração, tráfego de máquinas.

\section{PARAMETERS OF SOIL-MACHINE IN FUNCTION OF THE AMOUNT OF COVER RESIDUES AND DIFFERENT FERTILIZER DEPOSITION DEPTHS IN DIRECT DRILLING}

\begin{abstract}
The continuous and inadequate machine traffic on soils under direct drilling has been changing the soil physical and mechanical properties, influencing therefore crop productivity. The experiment was carried out at the Agricultural Research Station of the Universidade Federal do Rio Grande do Sul (Eldorado do Sul, RS, Brazil) on Typic Paleudlt. The main aim of the work was to measure coulter draft requirements and physical attributes under black oats (Avena strigosa Schieb) and common vetch (CV) (Vicia sativa $L$.) partially decomposed. The experimental design was carried out in randomized blocks, with split-split-plots and three repetitions. The main treatments were plots with different amount of residues of the winter crop $(0,1,3 ; 2,6 ; 3,2 ; 3,8$ and $5,1 \mathrm{Mg} \mathrm{ha}^{-1}$ ), sub-plots were two working depth of the driller chisel-type furrow opener, and two traffic conditions (combine and tractor wheel traffic).The physical characteristics of the soil were influenced by the traffic tracks. The whole tractor-drill was influenced by the depths of fertilizer shanks and traffic of traffic tracks and combine.
\end{abstract}

KEYWORDS: physical soil parameter, power requirement, machine traffic.

\footnotetext{
${ }^{1}$ Pesquisa financiada com recursos da CAPES.

${ }^{2}$ Eng $^{\underline{a}}$ Agrônoma, doutoranda do Programa de Pós-Graduação em Ciência do Solo, UFLA, Lavras - MG, karinamarie2@ hotmail.com

${ }^{3}$ Eng ${ }^{\text {o }}$ Agrônomo, Prof. Associado, Depto. de Solos, Faculdade de Agronomia, UFRGS, Porto Alegre - RS, renatole@ufrgs.br

${ }^{4}$ Eng ${ }^{\mathrm{o}}$ Agrônomo, Prof. Adjunto 2, Depto. de Solos, Faculdade de Agronomia, UFRGS, Porto Alegre - RS, trein@ufrgs.br

${ }^{5}$ Eng $^{\mathrm{o}}$ Agrônomo, Pesquisador do Centro Nacional de Pesquisa da Soja (Embrapa Soja), Área de Manejo do Solo e da Cultura, henridebiasi@yahoo.com.br

${ }^{6}$ Eng ${ }^{0}$ Agrônomo, Doutorando em Ciência do Solo, UFRGS, Área de Mecanização Agrícola, Faculdade de Agronomia, UFRGS, agroconte@yahoo.com.br

Recebido pelo Conselho Editorial em: 7-4-2008

Aprovado pelo Conselho Editorial em: 9-7-2009
} 


\section{INTRODUÇÃO}

A compactação do solo é resultante da combinação entre o tempo de permanência da carga aplicada e o número de vezes que o solo é submetido a uma nova carga, sendo que o conhecimento das interações com o solo, como a pressão de inflação do pneu, tipo de pneu, carga por eixo das máquinas e a intensidade de tráfego são os principais fatores contribuintes para a compactação dos solos agrícolas.

Visando à otimização do conjunto trator-semeadora, é necessário o conhecimento da força de tração exercida pela semeadora e o requerimento de cada tipo de mecanismo sulcador. A importância básica de avaliar a compactação do solo prende-se ao fato de a mesma oferecer resistência ao esforço tratório e ao perfeito desenvolvimento das culturas (ANDREOLLA \& GABRIEL FILHO, 2006). Entre os fatores que interferem na tração, a condição da superfície do solo é fator determinante, todavia, nos modelos propostos para determinar a eficiência de um trator em desenvolver tração em condições de campo, não se contempla o tipo de cobertura vegetal presente sobre o solo.

Destaca-se a importância de conhecer o desempenho sobre a cobertura vegetal devido aos grandes avanços dos sistemas conservacionistas, entre eles a semeadura direta. A eficiência de um trator para desenvolver esforço tratório depende da interação entre o rodado e o solo, envolvendo complexo conjunto de fatores: característica do rodado, patinhagem, transferência de peso do trator, tipo de solo, umidade, estado de compactação, tipo de cobertura do solo, entre outros, que proporcionam diferentes condições de trabalho e interferem no desempenho do trator (GABRIEL FILHO et al., 2004).

A aplicação de cargas dinâmicas por rodados e implementos agrícolas no solo produz tensões na interface solo/pneu e solo/implemento em superfície e profundidade, respectivamente. Essas tensões compactam as diferentes camadas do solo (HORN \& LEBERT, 1994); caso esse carregamento dinâmico exceda a resistência interna do solo, mudanças nas propriedades físicas das camadas mais profundas ocorrerão. De acordo com BALL et al. (1997), a densidade do solo é significativamente elevada após o tráfego de máquinas agrícolas, com redução da macroporosidade e da condutividade hidráulica.

As modificações nas propriedades físicas do solo, decorrentes do tráfego de máquinas nas operações agrícolas, têm sido amplamente estudadas, ressaltando-se os efeitos negativos da compactação do solo sobre a produtividade das culturas. Contudo, nas últimas décadas, a mecanização das operações agrícolas tem-se intensificado, resultando em aumento na carga aplicada pelas máquinas, provocando, na maioria dos casos, a degradação física do solo em superfície e subsuperfície (YAVUZCAN et al., 2005). O presente trabalho teve os objetivos de obter informações sobre os atributos físicos do solo e quantificar a força de tração.

\section{MATERIAL E MÉTODOS}

O experimento foi conduzido na Estação Experimental Agronômica da Universidade Federal do Rio Grande do Sul, localizada no município de Eldorado do Sul - RS, no ano agrícola de 2006/2007. O solo foi classificado como Argissolo Vermelho distrófico típico (EMBRAPA, 2006). A área experimental apresenta declividade média de $0,02 \mathrm{~m} \mathrm{~m}^{-1}$, com precipitação média anual de $1.440 \mathrm{~mm}$ e clima subtropical de verão úmido quente (Cfa) (BERGAMASCHI et al., 2003).

As parcelas experimentais possuíam $7 \mathrm{~m}$ de comprimento por $5 \mathrm{~m}$ de largura, sendo essas subdivididas $(2,5 \mathrm{~m} \times 7 \mathrm{~m})$ em função da profundidade de atuação dos sulcadores de adubo da semeadora-adubadora a 0,06 e $0,12 \mathrm{~m}$ de profundidade. Nas subsubparcelas, considerou-se o tráfego dos rodados do trator e da colhedora.

Antecedendo à semeadura do milho, foi dessecado o consórcio de aveia-preta e ervilhaca, o qual foi colhido mecanicamente com colhedora autopropelida de grãos munida de plataforma de corte convencional e picador de palhas. Durante a colheita, a palha proveniente do saca-palhas e das 
peneiras foi coletada em lona plástica e suspensa manualmente por quatro pessoas. Após, pesou-se a quantidade de palha necessária em cada parcela, sendo distribuída manual e uniformemente sobre as mesmas.

Os tratamentos foram constituídos pelas doses de resíduos da cultura de inverno sobre o solo, sendo $0 ; 2 ; 4 ; 5 ; 6$ e $8 \mathrm{t} \mathrm{ha}^{-1}$ de palha de aveia-preta consorciada com ervilhaca, com três repetições. Após 104 dias do manejo, houve redução média de 36\% na massa do resíduo vegetal aplicado. Assim as doses reais utilizadas no momento da semeadura do milho e medição da força de tração foram: $0 ; 1,3 ; 2,6 ; 3,2 ; 3,8$ e $5,1 \mathrm{Mg} \mathrm{ha}^{-1}$. Para determinar a massa seca da cobertura vegetal, utilizou-se de um quadro com dimensões de $0,5 \times 0,5 \mathrm{~m}$, coletando-se a palhada no seu interior. Em seguida, essa foi levada para secagem em estufa a $65^{\circ} \mathrm{C}$, por 72 horas.

A área experimental foi estruturalmente organizada e manejada de forma a proporcionar tráfego controlado. Nas subparcelas, foram utilizadas duas profundidades de atuação das hastes sulcadoras. Nas subsubparcelas, houve zonas trafegadas pelos rodados da colhedora e do trator, em localização diferenciada. O delineamento experimental foi em blocos casualizados, sendo, nas parcelas principais, seis doses de resíduos vegetais; nas subparcelas, duas profundidades de atuação da haste sulcadora de adubo, e nas subsubparcelas, os tráfegos dos rodados do trator e da colhedora.

O milho foi semeado utilizando-se de semeadora-adubadora marca Vence Tudo, modelo AS 11500, de precisão, montada, de 3 linhas espaçadas em $0,90 \mathrm{~m}$. A profundidade de deposição das sementes foi regulada para $0,05 \mathrm{~m}$, enquanto a aplicação do adubo foi regulada para duas profundidades $(0,06$ e $0,12 \mathrm{~m})$. O trator utilizado para tracionar a semeadora-adubadora foi o John Deere modelo 5600, 4x2 TDA, com potência máxima no motor de $53 \mathrm{~kW}(75 \mathrm{cv})$, com pneus traseiros 18.4-30 R1 e dianteiros 12.4-24 R1, com pressão de inflação de $95 \mathrm{kPa}$ e $110 \mathrm{kPa}$, respectivamente.

Antes da semeadura do milho safrinha, realizaram-se as análises dos atributos físicos do solo, como macroporosidade, microporosidade, porosidade total, densidade do solo, segundo EMBRAPA (1997). As amostras foram coletadas apenas nos tratamentos em que, por ocasião do manejo das culturas de inverno (aveia+ervilhaca), tiveram as doses de 0; 4 e $8 \mathrm{Mg} \mathrm{ha}^{-1}$ de resíduos sobre o solo, nas zonas de tráfegos dos rodados do trator e da colhedora e na zona sem tráfego, nas camadas de 0,03-0,06 m e 0,12-0,15 m, com quatro repetições. A resistência à penetração foi realizada nos

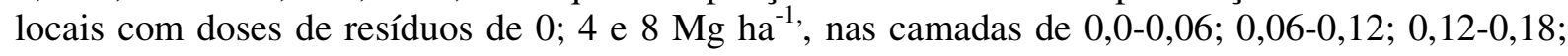
0,18-0,24; 0,24-0,30 m, utilizando penetrômetro marca PenetroLOG, modelo PLG1020, de acordo com a Norma ASAE S313.3 (ASAE, 2004).

Após essa etapa, realizou-se a semeadura do milho em 14 de fevereiro de 2007, com sementes AGN 2012 Agromen, sendo a semeadora regulada para dispor 65 mil sementes por hectare. A adubação usada na ocasião da semeadura foi de $400 \mathrm{~kg} \mathrm{ha}^{-1}$ da formulação NPK 5-20-20.

A força de tração demandada nas hastes sulcadoras de adubo, no momento da semeadura do milho (104 dias após o manejo da cobertura vegetal), foi avaliada por meio de "strain gages" ou extensiômetros, sensores eletrônicos instalados nos suportes das mesmas, avaliando-se a da posição central (tráfego do rodado da colhedora) e a da extremidade direita da semeadora-adubadora, essa última coincidente com o rastro do rodado do trator. No momento da semeadura do milho safrinha, o solo apresentou umidade gravimétrica média de $0,18 \mathrm{~kg} \mathrm{~kg}^{-1}$. Os dados de esforço de tração foram armazenados em unidade armazenadora de dados (datalogger) da marca Campbell Scientific, modelo CR23X. A partir desses dados, calculou-se a demanda de tração (N), em função de curva de calibração pertinente a cada haste instrumentada, para cada profundidade do sulcador de adubo. As avaliações foram realizadas em cada subsubparcela experimental, durante a semeadura do milho, com seis repetições. 


\section{RESULTADOS E DISCUSSÃO}

Na Tabela 1, verifica-se que não houve diferença significativa para a macroporosidade entre o tráfego da colhedora e do trator, sendo que o local sem tráfego apresentou maior valor de macroporosidade do solo. Para a microporosidade, observa-se que houve diferença significativa para as doses de resíduos vegetais. Já no local onde não havia nenhuma quantidade de resíduos, foi observado maior valor médio de microporosidade, comparado às doses de 4 e $8 \mathrm{Mg} \mathrm{ha}{ }^{-1}$. SCHÄFFER et al. (2007) e TARAWALLY et al. (2004) também verificaram reduções na macroporosidade em função do tráfego de máquinas, sendo que a microporosidade não foi alterada e/ou houve até pequeno incremento.

TABELA 1. Macroporosidade, microporosidade, porosidade total e densidade do solo nos locais sem tráfego, com tráfego do rodado do trator e da colhedora, em função das doses de resíduos antes da implantação da cultura do milho. Macroporosity, microporosity, total porosity, soil bulk density of soil without tractor wheel traffic, with tractor wheel and combine wheel traffic, in function of crop residues before corn seeding.

\begin{tabular}{|c|c|c|c|c|}
\hline \multirow{2}{*}{$\begin{array}{l}\text { Doses de Resíduos } \\
\left(\mathrm{Mg} \mathrm{ha}^{-1}\right)\end{array}$} & \multicolumn{3}{|c|}{ Tráfego Controlado } & \multirow[b]{2}{*}{ Média $^{2}$} \\
\hline & Trator & Colhedora & Sem tráfego & \\
\hline \multicolumn{5}{|c|}{ - } \\
\hline 0 & 0,09 & 0,10 & 0,13 & 0,11 \\
\hline 4 & 0,10 & 0,11 & 0,12 & 0,11 \\
\hline 8 & 0,10 & 0,11 & 0,13 & 0,11 \\
\hline Média ${ }^{2}$ & $0,10 \mathrm{~A}$ & $0,11 \mathrm{~A}$ & $0,13 \mathrm{~B}$ & 0,11 \\
\hline \multicolumn{5}{|c|}{--Microporosidade $\left(\mathrm{m}^{3} \mathrm{~m}^{-3}\right)$} \\
\hline 0 & $0,37 \mathrm{Aa}$ & $0,32 \mathrm{~B}$ & $0,33 \mathrm{~B}$ & $0,34 \mathrm{a}$ \\
\hline 4 & $0,32 \mathrm{Ab}$ & $0,32 \mathrm{~A}$ & $0,32 \mathrm{~A}$ & $0,32 \mathrm{~b}$ \\
\hline 8 & $0,33 \mathrm{Ab}$ & $0,32 \mathrm{AB}$ & $0,31 \mathrm{~B}$ & $0,32 \mathrm{~b}$ \\
\hline Média $^{2}$ & $0,34 \mathrm{~A}$ & $0,32 \mathrm{~B}$ & $0,32 \mathrm{~B}$ & 0,33 \\
\hline \multicolumn{5}{|c|}{ Porosidade total $\left(\mathrm{m}^{3} \mathrm{~m}^{-3}\right)$} \\
\hline 0 & 0,45 & 0,42 & 0,46 & $0,45 \mathrm{a}$ \\
\hline 4 & 0,42 & 0,42 & 0,44 & $0,43 \mathrm{~b}$ \\
\hline 8 & 0,43 & 0,43 & 0,44 & $0,43 \mathrm{~b}$ \\
\hline Média $^{2}$ & $0,44 \mathrm{AB}$ & $0,43 \mathrm{~B}$ & $0,45 \mathrm{~A}$ & 0,44 \\
\hline \multicolumn{5}{|c|}{ 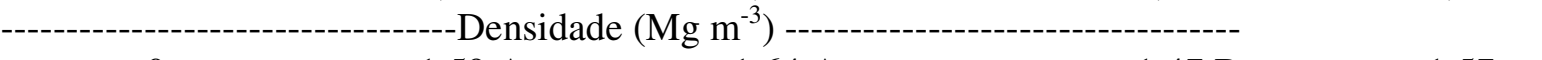 } \\
\hline 0 & $1,59 \mathrm{~A}$ & $1,64 \mathrm{Aa}$ & $1,47 \mathrm{~B}$ & 1,57 \\
\hline 4 & 1,55 & $1,52 \mathrm{~b}$ & 1,53 & 1,53 \\
\hline 8 & 1,53 & $1,53 \mathrm{ab}$ & 1,45 & 1,50 \\
\hline Média $^{2}$ & $1,56 \mathrm{~A}$ & $1,56 \mathrm{~A}$ & $1,48 \mathrm{~B}$ & 1,54 \\
\hline
\end{tabular}

${ }^{\mathrm{T}}$ Massa aplicada em 2-11-2006, logo após manejo da plantas de cobertura de inverno.

Macroporosidade: C.V. Doses de resíduos $=18,74 \%$; C.V. Tráfego $=24,57 \%$; Macroporosidade: C.V. Doses de resíduos $=6,47 \%$; C.V. Tráfego $=5,35 \%$. Porosidade: C.V. Doses de resíduos $=4,80 \%$; C.V. Tráfego $=6,08 \%$. Densidade: C.V. Doses de resíduos $=8,62 \%$; C.V. Tráfego $=5,56 \% .{ }^{2}$ Médias seguidas de mesma letra maiúscula na linha, minúscula na coluna e ausência de letras não diferem entre si, pelo teste de Tukey $(\mathrm{P}<0,05 \%)$.

Nota-se que a área correspondente ao tráfego do rodado do trator apresentou maior valor médio de microporosidade do que nas condições sem tráfego e trafegado pelos rodados da colhedora.

No tratamento sem resíduos vegetais, observou-se maior valor médio de porosidade total, comparado àqueles em que houve adição de resíduos vegetais. A porosidade total foi maior na área sem tráfego do que nos locais de solo trafegado pelos rodados da colhedora e não diferiu daqueles trafegados pelos rodados do trator. A densidade do solo não diferiu significativamente entre o tráfego do rodado do trator e da colhedora e foi menor nos locais sem tráfego (Tabela 1). Segundo 
SCHÄFFER et al. (2007), a densidade do solo e a porosidade total constituem-se em variáveis pouco sensíveis aos efeitos do tráfego, de modo que, em alguns casos, as pressões exercidas pelos rodados não as modificam.

Ao comparar as camadas de solo (Tabela 2), verifica-se que a macroporosidade e a porosidade total na camada de 0,03-0,06 m apresentaram maiores valores médios, comparadas à camada de 0,12-0,15 m. Na camada de 0,12-0,15 m, nota-se que os valores de macroporosidade são considerados críticos. Segundo IMHOFF (2002), valores de porosidade de aeração abaixo do nível considerado crítico (10\%), por sua vez, são atingidos sob menores teores de água; quando se referem ao desenvolvimento das plantas, os maiores prejuízos parecem estar relacionados às relações hídricas e de aeração do solo, bem como ao aumento da resistência do solo à penetração das raízes.

TABELA 2. Macroporosidade, microporosidade, porosidade total e densidade do solo nos locais sem tráfego, com tráfego do trator e da colhedora em função da camada de solo, antes da implantação da cultura do milho safrinha. Macroporosity, microporosity, total porosity, soil bulk density without tractor wheel traffic, with tractor and combine wheel traffic, in function of working depth before corn seeding.

\begin{tabular}{|c|c|c|c|c|}
\hline \multirow{2}{*}{$\begin{array}{c}\text { Camada } \\
\text { (m) }\end{array}$} & \multicolumn{3}{|c|}{ Tráfego Controlado } & \multirow[b]{2}{*}{ Média $^{1}$} \\
\hline & Trator & Colhedora & Sem tráfego & \\
\hline \multicolumn{5}{|c|}{ 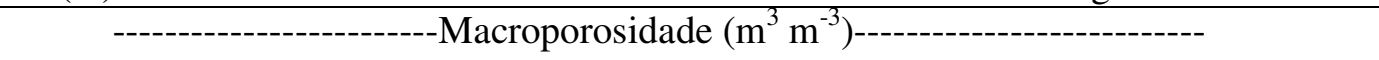 } \\
\hline $0,03-0,06$ & 0,11 & 0,11 & 0,15 & $0,12 \mathrm{a}$ \\
\hline $0,12-0,15$ & 0,09 & 0,10 & 0,11 & $0,10 \mathrm{~b}$ \\
\hline Média ${ }^{1}$ & $0,10 \mathrm{~A}$ & $0,11 \mathrm{~A}$ & $0,13 \mathrm{~B}$ & 0,11 \\
\hline \multicolumn{5}{|c|}{ 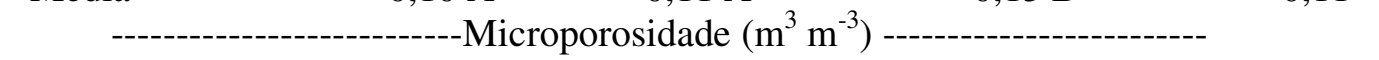 } \\
\hline $0,03-0,06$ & 0,33 & 0,32 & 0,32 & $0,32 \mathrm{a}$ \\
\hline $0,12-0,15$ & 0,35 & 0,33 & 0,32 & $0,33 \mathrm{~b}$ \\
\hline Média ${ }^{1}$ & $0,34 \mathrm{~A}$ & $0,32 \mathrm{~B}$ & $0,32 \mathrm{~B}$ & 0,33 \\
\hline \multicolumn{5}{|c|}{--Porosidade total $\left(\mathrm{m}^{3} \mathrm{~m}^{-3}\right)$} \\
\hline $0,03-0,06$ & 0,44 & 0,43 & 0,47 & $0,44 \mathrm{a}$ \\
\hline $0,12-0,15$ & 0,44 & 0,43 & 0,43 & $0,43 \mathrm{~b}$ \\
\hline Média ${ }^{1}$ & $0,44 \mathrm{AB}$ & $0,43 \mathrm{~B}$ & $0,45 \mathrm{~A}$ & 0,44 \\
\hline \multicolumn{5}{|c|}{--Densidade do solo $\left(\mathrm{Mg} \mathrm{m}^{-3}\right)$} \\
\hline $0,03-0,06$ & 1,53 & 1,51 & 1,43 & $1,49 \mathrm{a}$ \\
\hline $0,12-0,15$ & 1,58 & 1,62 & 1,54 & $1,58 \mathrm{~b}$ \\
\hline Média ${ }^{1}$ & $1,56 \mathrm{~A}$ & $1,56 \mathrm{~A}$ & $1,48 \mathrm{~B}$ & 1,54 \\
\hline
\end{tabular}

Macroporosidade: C.V. Tráfego $=24,57 \%$; C.V. Profundidade $=25,99 \%$; Microporosidade: C.V. Tráfego $=5,35 \%$; C.V. Profundidade $=4,49 \%$; Porosidade: C.V. Tráfego $=6,08 \%$; C.V. Profundidade $=6,25 \%$; Densidade: C.V. Tráfego $=5,56 \%$; C.V. Profundidade $=6,31 \% .{ }^{1}$ Médias seguidas de letras maiúsculas diferentes na linha e minúscula na coluna diferem entre si, pelo teste de Tukey $(\mathrm{P}<0,05 \%)$.

A microporosidade e a densidade do solo foram menores na camada de 0,03-0,06 $\mathrm{m}$ do que na camada de 0,12-0,15 m. Os valores obtidos para a densidade do solo foram inferiores, comparados com os resultados obtidos por XAVIER (2005). Esse fato pode estar relacionado ao emprego de plantas de cobertura de inverno; várias pesquisas têm comprovado que o uso de culturas de cobertura na recuperação de solos compactados engloba o aumento do teor de matéria orgânica do solo (MOS). Reduções na densidade do solo, em virtude do aumento do teor de MOS, foram relatadas por JARECKI et al. (2005).

Os valores obtidos para o índice de cone (IC), em função das doses de resíduos vegetais e tráfego controlado, são apresentados na Tabela 3. A aplicação de doses de resíduos vegetais de 4 e 8 $\mathrm{Mg} \mathrm{ha}^{-1}$ sobre a superfície do solo contribuiu para a redução de parte da pressão exercida pelos pneus do trator e da colhedora, visto que, no tratamento sem resíduo vegetal $\left(0 \mathrm{Mg} \mathrm{ha}^{-1}\right)$, foi observado maior valor médio de IC. Apesar de não haver diferença significativa entre as doses de 4 
e $8 \mathrm{Mg} \mathrm{ha}^{-1}$, constata-se que o resíduo vegetal dissipou parte da energia compactante devido ao tráfego de máquinas. Neste estudo, houve redução média de $14 \%$ no IC ao comparar a parcela sem resíduos com as parcelas com doses de 4 e $8 \mathrm{Mg} \mathrm{ha}^{-1}$.

TABELA 3. Índice de cone (MPa), em função das doses de resíduos vegetais, tráfego controlado e camada de solo, antes da implantação da cultura do milho. Cone index (MPa) in function of crop residues, controlled traffic lanes and working depth before corn seeding.

\begin{tabular}{ccccc}
\hline $\begin{array}{c}\text { Doses de Resíduos } \\
\left(\mathrm{Mg} \mathrm{ha}^{-1}\right)\end{array}$ & \multicolumn{3}{c}{ Tráfego Controlado } & \multirow{2}{*}{ Média $^{2}$} \\
\cline { 2 - 4 } & Trator & Colhedora & Sem Tráfego & \\
\hline 0 & $1,46 \mathrm{aA}$ & $1,55 \mathrm{aA}$ & $1,13 \mathrm{aB}$ & 1,38 \\
8 & $1,22 \mathrm{bA}$ & $1,28 \mathrm{bA}$ & $1,11 \mathrm{aB}$ & 1,20 \\
Média $^{2}$ & $1,23 \mathrm{bA}$ & $1,26 \mathrm{bA}$ & $1,04 \mathrm{aB}$ & 1,18 \\
\hline Camada (m) & 1,30 & 1,37 & 1,09 & 1,25 \\
\hline $0,00-0,06$ & $0,17 \mathrm{dA}$ & $0,15 \mathrm{cA}$ & $0,09 \mathrm{dA}$ & 0,14 \\
$0,06-0,12$ & $1,19 \mathrm{c} \mathrm{A}$ & $1,29 \mathrm{bA}$ & $0,98 \mathrm{cB}$ & 1,15 \\
$0,12-0,18$ & $1,62 \mathrm{bB}$ & $1,78 \mathrm{aA}$ & $1,31 \mathrm{bC}$ & 1,57 \\
$0,18-0,24$ & $1,75 \mathrm{abA}$ & $1,82 \mathrm{aA}$ & $1,48 \mathrm{aB}$ & 1,68 \\
$0,24-0,30$ & $1,79 \mathrm{aA}$ & $1,79 \mathrm{aA}$ & $1,59 \mathrm{aB}$ & 1,72 \\
Média $^{2}$ & 1,30 & 1,37 & 1,09 & 1,25 \\
\hline
\end{tabular}

${ }^{\mathrm{T}}$ Massa aplicada em 2-11-2006, logo após manejo da plantas de cobertura de inverno. C.V. Doses de resíduos =22,39\%; C.V. Tráfego $=10,13 \% .{ }^{2}$ Médias seguidas de mesma letra maiúscula na linha e minúscula na coluna não diferem entre si, pelo teste de Tukey $(\mathrm{P}<0,05 \%)$.

$\mathrm{Na}$ área correspondente ao tráfego do rodado da colhedora, foi apresentado maior valor médio de IC, o que está relacionado à distribuição de carga no eixo (4.950 kg no eixo dianteiro, ou seja, $70 \%$ da carga) e $2.250 \mathrm{~kg}$ no eixo traseiro, ou seja, $30 \%$ da massa total de $7.200 \mathrm{~kg}$. Já o trator com massa total de $3.835 \mathrm{~kg}$, possuía $1.530 \mathrm{~kg}$ sobre o eixo dianteiro e $2.305 \mathrm{~kg}$ sobre o traseiro. A pressão de contato dos pneus dianteiros e traseiros com o solo foi de 173 e $260 \mathrm{kPa}$ e de 115 e $120 \mathrm{kPa}$, respectivamente, para a colhedora e para o trator, notando-se que a pressão de contato na colhedora é mais elevada do que a do trator.

Os valores de índice de cone em função do tráfego controlado e camadas de solo também são apresentados na Tabela 3. Na camada de 0,00-0,06 m, não houve diferença significativa para o tráfego controlado. Na camada de 0,06-0,12 m, o menor valor de IC foi obtido no tratamento sem tráfego. Na camada de 0,12-0,18 m, houve diferença significativa entre todos os tratamentos de tráfego controlado, verificando-se o menor valor de IC no local sem tráfego de rodados, e o maior sob tráfego de rodados da colhedora. Verifica-se que houve aumento IC à medida que houve incremento da profundidade do solo. Segundo ALAKUKKU et al. (2003), o peso das máquinas e a pressão que as mesmas exercem no solo influenciam diretamente na profundidade e na distribuição dessa camada mais compactada, que geralmente faz parte do subsolo.

Conforme a teoria da transmissão de tensões no solo (TREIN, 1995), esperam-se maiores diferenças nos valores de IC com o aumento da profundidade. Apesar de os pneus da colhedora e do trator terem as mesmas dimensões e forma construtiva, os mesmos suportam cargas diferentes, resultando em distintas pressões de contato pneu-solo. O máximo de deformação volumétrica esperado aconteceria em profundidades maiores que a amostrada, pois a falha do solo só estaria totalmente confinada a profundidades maiores que $0,20 \mathrm{~m}$ para o tipo de pneu utilizado.

Na Tabela 4, observa-se que não houve diferença significativa no teor de água do solo nos tratamentos de 0 e $4 \mathrm{Mg} \mathrm{ha}^{-1}$, sendo os maiores valores encontrados na dose de $8 \mathrm{Mg} \mathrm{ha}^{-1}$. 
TABELA 4. Umidade do solo em função da aplicação das doses de resíduos vegetais realizada no momento da avaliação da resistência à penetração. Moisture related to crop residues at soil penetration resistance evaluation.

\begin{tabular}{|c|c|c|c|c|}
\hline \multirow{2}{*}{$\begin{array}{c}\text { Camada } \\
(\mathrm{m})\end{array}$} & \multicolumn{3}{|c|}{ Doses de Resíduos Vegetais $\left(\mathrm{Mg} \mathrm{ha}^{-1}\right)^{1}$} & \multirow{2}{*}{ Média $^{2}$} \\
\hline & 0 & 4 & 8 & \\
\hline & \multicolumn{4}{|c|}{ - } \\
\hline $0,00-0,06$ & 0,13 & 0,15 & 0,17 & $0,15 \mathrm{~b}$ \\
\hline $0,06-0,12$ & 0,15 & 0,17 & 0,17 & $0,16 \mathrm{ab}$ \\
\hline $0,12-0,18$ & 0,17 & 0,16 & 0,18 & $0,17 \mathrm{ab}$ \\
\hline $0,18-0,24$ & 0,16 & 0,17 & 0,18 & $0,17 \mathrm{ab}$ \\
\hline $0,24-0,30$ & 0,17 & 0,17 & 0,20 & $0,18 \mathrm{a}$ \\
\hline Média $^{2}$ & $0,15 \mathrm{~B}$ & $0,16 \mathrm{~B}$ & $0,18 \mathrm{~A}$ & 0,17 \\
\hline
\end{tabular}

Na Tabela 5, apresentam-se os resultados referentes à força de tração na haste sulcadora da semeadora-adubadora, responsável pela deposição de adubo, nas profundidades de atuação de 0,06m e 0,12 m, na área correspondente ao tráfego do rodado do trator e da colhedora.

Nas duas profundidades de atuação do sulcador de adubo $(0,06 \mathrm{~m}$ e $0,12 \mathrm{~m})$, a força de tração não foi influenciada pelas doses de resíduos vegetais. Quando o sulcador passou a operar de $0,06 \mathrm{~m}$ a $0,12 \mathrm{~m}$ de profundidade, houve incremento de $76 \%$ na força de tração medida no sulcador da semeadora. XAVIER (2005) também obteve maior demanda de força de tração em função do aumento da profundidade de atuação da haste sulcadora da semeadora-adubadora. Contudo, os incrementos obtidos por esse autor foram maiores, chegando a $150 \%$.

CEPIK et al. (2005) verificaram que a força de tração, medida na haste sulcadora de adubo da semeadora-adubadora, aumentou entre $70 \%$ e $130 \%$ em função do aumento da profundidade de trabalho, de 0,06 m para 0,12 m, em função do teor de água do solo. $\mathrm{O}$ aumento da velocidade de deslocamento resultou em maiores valores de esforço de tração apenas na condição de friabilidade e com sulcador operando a $0,12 \mathrm{~m}$ de profundidade.

TABELA 5. Força de tração (N) na haste sulcadora de adubo na profundidade de 0,06 e 0,12 m e no tráfego de rodados do trator e da colhedora, na operação de semeadura do milho em função das doses de resíduos aplicados sobre superfície do solo. Draft to work the furrow openers of a planter fertilizer shanks to depths of $0.06 \mathrm{e} 0.12 \mathrm{~m}$ on tractor and combine wheel traffic lanes, related to the crop residues on soil.

\begin{tabular}{ccccc}
\hline \multirow{2}{*}{$\begin{array}{c}\text { Doses de Resíduos } \\
\left(\mathrm{Mg} \mathrm{ha}^{-1}\right)\end{array}$} & \multicolumn{2}{c}{$\begin{array}{c}\text { Profundidade de Atuação } \\
\text { da Haste Sulcadora }\end{array}$} & \multicolumn{2}{c}{ Tráfego do Rodado } \\
\cline { 2 - 5 } & $0,06 \mathrm{~m}$ & $0,12 \mathrm{~m}$ & Trator & Colhedora \\
\hline 0 & 852 & 1.409 & 1.307 & 955 \\
1,32 & 758 & 1.403 & 1.237 & 925 \\
2,64 & 768 & 1.353 & 1.240 & 881 \\
3,25 & 792 & 1.423 & 1.270 & 945 \\
3,84 & 768 & 1.398 & 1.261 & 905 \\
5,12 & 813 & 1.383 & 1.263 & 934 \\
\hline Média & $792 \mathrm{~A}$ & $1.395 \mathrm{~B}$ & $1.263 \mathrm{~A}$ & $924 \mathrm{~B}$ \\
\hline
\end{tabular}

C.V. Doses de resíduos $=10,00 \%$; C.V. Profundidades $=29 \%$; C.V. Tráfego $=10,78 \%$. ${ }^{1}$ Médias seguidas de mesma letra maiúscula na linha e ausência de letra na coluna não diferem entre si, pelo teste de Tukey $(\mathrm{P}<0,05 \%)$.

A força de tração requerida pelas hastes de adubo foi aproximadamente $27 \%$ superior na área trafegada pelo rodado do trator em relação ao local trafegado pelo rodado da colhedora. As doses de 
resíduos vegetais não influenciaram na força de tração nas duas profundidades de atuação do sulcador de adubo e no tráfego dos rodados de trator e colhedora. Resultados semelhantes foram encontrados em trabalhos realizados por XAVIER (2005) e CEPIK (2006).

Ao relacionar as variáveis IC e força de tração medida nas hastes sulcadoras de adubo, o coeficiente de correlação foi significativo, indicando que uma dessas variáveis pode indicar o quanto à outra é capaz de variar. Essa correlação entre IC e força de tração foi obtida nas profundidades de 0,06 e 0,12 m (Figuras 1 e 2). O IC é um método clássico e eficiente de se diagnosticar a compactação do solo, e essa medida apresentam correlação significativa com a força de tração medida nas hastes sulcadoras. Dessa forma, o uso de hastes sulcadoras instrumentadas para aquisição do esforço de tração pode fornecer diagnóstico da condição física do solo, principalmente com relação à compactação e assim estimar avaliações específicas para esse fim.

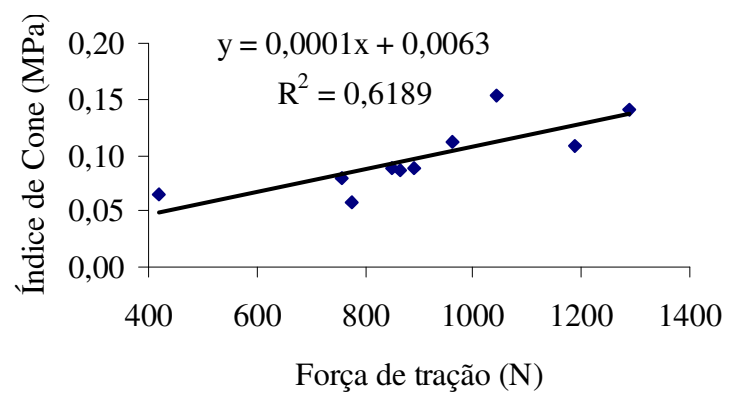

FIGURA 1. Relação entre força de tração e índice de cone na camada de 0,00 $0,06 \mathrm{~m}$. Relationship between draft requirement and cone index in the surface layer $(0.00$ to $0.06 \mathrm{~m}$ ).

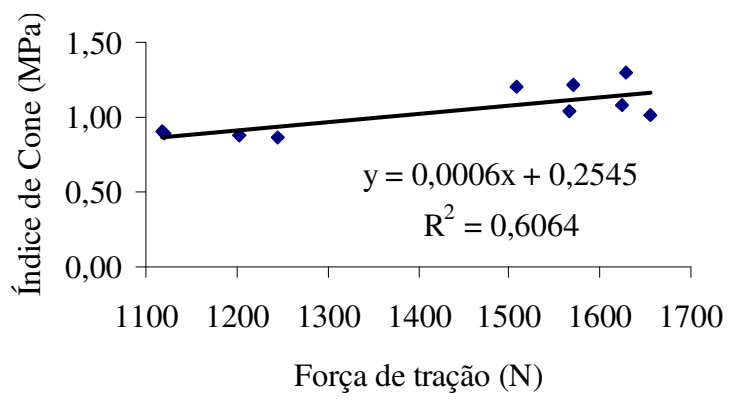

FIGURA 2. Relação entre força de tração e índice de cone na camada de 0,00-0,12 m. Relationship between draft requirement and cone index in the 0.12 m layer.

\section{CONCLUSÕES}

A microporosidade e a densidade do solo apresentaram maiores valores nos locais de tráfego de rodados, sendo que a resistência à penetração foi maior no tráfego dos rodados da colhedora. A força de tração foi influenciada pela profundidade de atuação da haste sulcadora $(0,06$ e $0,12 \mathrm{~m})$ e pelo tráfego dos rodados, não sendo afetada pelas doses de resíduos vegetais.

\section{REFERÊNCIAS}

ALAKUKKU, L.; WEISSKOPF, P.; CHAMEN, W.C.T.; TIJINK, F.G.J.; VAN DER LINDEN, J.P.; PIRES, S.; SOMMER, C.; SPOOR, G. Prevention strategies for field traffic-induced subsoil compaction: a review Part 1. Machine/soil interactions. Soil and Tillage Research, Amsterdam, v.73, n.1-2, p.145-160, 2003.

ANDREOLLA, V.R.M.; GABRIEL FILHO, A. Demanda de potência de uma semeadora com dois tipos de sulcadores em áreas compactadas pelo pisoteio de animais no sistema integração lavoura-pecuária. Engenharia Agrícola, Jaboticabal, v.26, n.3, p.768-776, 2006.

ASAE. AMERICAN SOCIETY OF AGRICULTURAL ENGINEERS. Soil Cone Penetrometer. ASAE S313.3. St. Joseph, 2004.

BALL, B.C.; CAMPBELL, D.J.; DOUGLAS, J.T.; HENSHALL, J.K.; O’SULLIVAN, M.F. Soil structural quality, compaction and land management. European Journal of Soil Science, Oxford, v.48, n.4, p.593-601, 1997.

BERGAMASCHI, H.; GUADAGNIN, M.R.; CARDOSO, L.S.; SILVA, M.I.G da. Clima da Estação Experimental da UFRGS. Porto Alegre: UFRGS, 2003. 77 p. 
CEPIK, C.T.C. Parâmetros de solo e máquinas em semeadura direta com doses de cobertura e configurações de deposição de fertilizante. 2006. 104 f. Tese (Doutorado em Ciência do Solo) Universidade Federal do Rio Grande do Sul, Porto Alegre, 2006.

CEPIK, C.T.C.; TREIN, C.R.; LEVIEN, R. Força de tração e volume de solo mobilizado por haste sulcadora em semeadura direta sobre campo nativo, em função do teor de água no solo, profundidade e velocidade de operação. Engenharia Agrícola, Jaboticabal, v.25, n.2, p.447-457, 2005.

EMBRAPA. EMPRESA BRASILEIRA DE PESQUISA AGROPECUÁRIA. Manual de métodos de análise de solo. 2.ed. Rio de Janeiro, 1997. $247 \mathrm{f}$.

EMBRAPA. EMPRESA BRASILEIRA DE PESQUISA AGROPECUÁRIA. Sistema Brasileiro de classificação de solos. Brasília, 2006. 306 p.

GABRIEL FILHO, A.; SILVA, S.L.; MODOLO, A.J.; SILVEIRA, J.C.M. Desempenho de um trator operando em solo com diferentes tipos de cobertura vegetal. Engenharia Agrícola, Jaboticabal, v.24, n.3, p.781-789, 2004.

HORN, R.; LEBERT, M. Soil compactability and compressibility. In: SOANE, B.D.; OUWERKERK, C. Van. Soil compaction in crop production. Amsterdam: Elsevier, 1994. p.45-69.

IMHOFF, S. Indicadores de qualidade estrutural e trafegabilidade de Latossolos e Argissolos Vermelhos. 2002. 94 f. Tese (Doutorado em Solos e Nutrição de Plantas) - Escola Superior de Agricultura "Luiz de Queiroz", Universidade de São Paulo, Piracicaba, 2002.

JARECKI, M.K.; LAL, R.; JAMES, R. Crop management effects on soil carbon sequestration on selected farmers' fields in Ortheastern Ohio. Soil and Tillage Research, Amsterdam, v.81, n.2, p.265-276, 2005.

SCHÄFFER, B.; ATTINGER, W.; SCHULIN, R. Compaction of restored soil by heavy agricultural machinery-Soil physical and mechanical aspects. Soil and Tillage Research, Amsterdam, v.93, n.1, p.28-43, 2007.

TARAWALLY, M.A.; MEDINA, H.; FRÓMETA, M.E.; ITZA, C. A. Field compaction at different soil-water status: effects on pore size distribution and soil water characteristics of a Rhodic Ferralsol in Western Cuba. Soil and Tillage Research, Amsterdam, v.76, n.2, p.95-103, 2004.

TREIN, C.R. The mechanics of soil compaction under wheels. 1995. 132 f. Tese (Doutorado) Cranfield University, Silsoe, 1995.

XAVIER, A. Comportamento da cultura da soja em função de resíduos culturais, mobilização do solo e irrigação, em semeadura direta. 2005. 99 f. Dissertação (Mestrado em Ciência do Solo) Universidade Federal do Rio Grande Sul, Porto Alegre, 2005.

YAVUZCAN, H.G.; MATTHIES, D.; AUERNHAMMER, H. Vulnerability of Bavarian silty loam soil to compaction under heavy whell traffic: impacts of tillage method and soil water content. Soil and Tillage Research, Amsterdam, v.84, n.2, p.200-215, 2005. 